\title{
Desnutrição infantil: experiência em uma comunidade rural
}

Recebido em: 12/04/2011

Aceito em: 26/07/2011

Mirna Albuquerque Frota'
Luciana Vilas Boas Polte $^{2}$
Ana Tereza Sá Nogueira $^{3}$
Ivna Silva Andrade

Objetivou-se retratar a desnutrição em menores de 6 anos nas famílias rurais, assim como investigar fatores relacionados. Estudo exploratório descritivo com abordagem qualitativa, realizado na comunidade do Sussuí, localizada em Quixadá, $\mathrm{CE}$, com quatro famílias de crianças desnutridas, utilizando a observação nas visitas domiciliares e entrevista semiestruturada. Realizou-se análise de conteúdo, resultando nas categorias: Conhecendo a Desnutrição Infantil, Prejuízos da Doença na Família e Cuidado Cultural. Concluiu-se que a desnutrição infantil é assunto abordado de forma frequente, mas com pouca resolutividade, observando-se índices elevados da doença devido à ausência de funcionalidade das políticas públicas, capazes de promover a saúde dos indivíduos.

Descritores: Transtornos da Nutrição Infantil, Família, Promoção da Saúde.

\section{Child malnutrition: experience in a rural community}

The aim of this work was to portray the malnutrition among children that are less than six years old in rural families as well as to investigate related factors. That is a descriptive exploratory study with a qualitative approach, carried out in the community Sussuí, located in Quixadá, CE with four families and their malnourished children, using the observation in the home visits and semi-structured interview. We conducted content analysis, resulting the following categories: Knowing the Child Malnutrition, Disease Losses in Family and Cultural Care. It was concluded that the subject matter child malnutrition is often approached but there is no resolution, observing high rates of disease due to lack of functionality of public policies that promote the health of individuals.

Descriptors: Child Nutrition Disorders, Family, Health Promotion.

\section{La desnutrición infantil: experiencia en una comunidad rural}

El objetivo era retratar la desnutrición en niños menores de seis años en los hogares rurales, así como investigar los factores relacionados. Estudio exploratorio descriptivo con enfoque cualitativo, realizado en La comunidad Sussuí, ubicada en Quixadá, CE con cuatro famílias con niños desnutridos, con la observación en las visitas domiciliarias y entrevistas semi-estructuradas. Se realizó un análisis de contenido, lo que resulta en las categorías: Conocer la desnutrición infantil, las pérdidas por enfermedades en la familia y Cuidado Cultural. Se concluyó que la desnutrición infantil es asunto frecuente, pero no hay solución para el problema observándose las altas tasas de enfermedad debido a la falta de funcionalidad de las políticas públicas que promuevan la salud de los individuos.

Descriptores: Trastornos de Nutrición Infantil, Familia, Promoción de la Salud..

\section{INTRODUÇÃO}

A taxa de mortalidade infantil representa risco de óbito tanto no período neonatal, nos primeiros 27 dias de vida, quanto no pós-neonatal, de 28 dias até o primeiro ano. A mortalidade neonatal está relacionada às condições da gestação, parto e integridade física do recém-nascido, e a pós-neonatal associa-se às condições socioeconômicas e do meio externo, com predomínio das causas infecciosas $^{(1)}$.

A implementação do Projeto Ajudando a Crescer (PAC) do Instituto Nordeste Cidadania, na comunidade do Sussuí, em Quixadá (CE), oportunizou a observação e análise a fim de reverter, na zona rural, o elevado índice de menores de 5 anos com baixo peso ${ }^{(2)}$. A desigualdade econômica do Brasil gera crescente miséria, fome, desnutrição e outros agravos comprometedores da qualidade de vida dos indivíduos, cabendo a Região Nordeste do país destaque em padrões de alimentação deficientes e baixo poder de compra das famílias rurais do semiárido, usuárias da agricultura de subsistência.

Compreende-se a epidemiologia nutricional pela má distribuição de renda nas Regiões Norte e Nordeste entre o meio rural e urbano, em comparação com as demais regiões. Os fatores ambientais atuam no surgimento de doenças que

1 Enfermeira. Doutora em Enfermagem. Docente do Curso de Enfermagem e Mestrado em Saúde Coletiva da Universidade de Fortaleza-UNIFOR. Líder do Núcleo de Pesquisa em Saúde da Criança -NUPESC/CNPq/UNIFOR. E-mail: mirnafrota@unifor.br.

2 Enfermeira assistencial.

3 Enfermeira da Estratégia Saúde da Família de Ocara- Ceará.

4 Enfermeira. Mestranda em Saúde Coletiva pela Universidade de Fortaleza -UNIFOR. Bolsista FUNCAP. Membro do Núcleo de Pesquisa em Saúde da Criança - NUPESC/CNPq/UNIFOR. 
comprometem a nutrição, bem como na oferta de alimentos à qual se interligam os determinantes socioeconômicos ${ }^{(3,4)}$.

As repercussões da desnutrição sobre os mecanismos de defesa na criança diferem no adulto, uma vez que a infância é caracterizada como período crítico para o desenvolvimento da defesa imunológica. Portanto, agravos nutricionais nesse período acarretarão reduzida resposta imune, a qual pode manter-se em longo prazo ${ }^{(5)}$. O semiárido nordestino tem difícil acesso à água de qualidade, mínimas condições de higiene e moradia, fome e morte de crianças. Nesse contexto, atraiu a atenção de autoridades responsáveis para promover a saúde e prevenir a desnutrição infantil.

Os fatores que se relacionam ao estilo e às condições de vida do indivíduo ou da coletividade são causas determinantes da cultura da comunidade. Nesse grupo, incluem-se características como costumes, crenças e hábitos de vida. Os aspectos de educação das famílias, nível de acessibilidade à saúde e trabalho estão vinculados à desnutrição, colocando-a como questão que deve ser tratada, sobretudo, como enfoque clínico-sanitário ${ }^{(6,7)}$.

Este estudo teve como objetivo retratar a desnutrição em menores de 6 anos nas famílias rurais, bem como investigar fatores relacionados.

\section{METODOLOGIA}

Estudo exploratório descritivo com abordagem qualitativa, em que a pesquisa descritiva não sofre interferência do pesquisador, ou seja, descreve o objeto de pesquisa, assim como procura descobrir a frequência em que o fenômeno ocorre, a natureza, característica, causas, relações e conexões com outros fenômenos( ${ }^{(8)}$.

Esta realizou-se na comunidade do Sussuí, em Quixadá, Ceará, atendida pelo Instituto Nordeste Cidadania, entidade civil fundada por funcionários do Banco do Nordeste para contribuir com a autossustentabilidade e o desenvolvimento das comunidades rurais. Do estudo, participaram quatro famílias de menores de 6 anos desnutridos.

A coleta de dados ocorreu por meio de visitas domiciliares, entrevista semiestruturada e perguntas norteadoras: "Como você percebe a saúde de seu filho? Que prejuízos a desnutrição infantil traz para seu filho e para a família? O que a família tem feito para tentar mudar essa situação?".

A organização dos dados baseou-se na interpretação dos resultados coletados e na inter-relação com a literatura pertinente ao assunto por meio da análise de conteúdo: préanálise, a exposição das falas; a descrição analítica, com os processos de codificação e de categorização; e a interpretação inferencial, com a explanação e a reflexão dos resultados ${ }^{(8)}$.

O estudo recebeu aprovação do Comitê de Ética em Pesquisa da Universidade de Fortaleza - Unifor, com parecer de número $03 / 220$, atendendo a todos os requisitos exigidos pela resolução 196/96 do Conselho Nacional de Saúde, incluindo a assinatura do Termo de Consentimento Livre e Esclarecido. Para garantir o anonimato, os informantes, foram representados por: M1, M2 (...).

\section{RESULTADOS E DISCUSSÃO}

A descrição das famílias buscou retratar e compreender o cotidiano da desnutrição infantil na zona rural: pais analfabetos sobrevivendo com renda inferior a meio salário mínimo oriunda do Bolsa Escola, agricultura, pesca e criação de animais; domicílios sem saneamento básico, energia elétrica e com água para necessidades pessoais proveniente de açude; casos pregressos e atuais de desnutrição infantil crônica e déficit de crescimento e desenvolvimento para a idade cronológica. A descrição e documentação das falas trouxeram significados contextuais da desnutrição infantil nas famílias da comunidade rural, emergindo as categorias: Desnutrição na Ótica Familiar, Prejuízos da Doença na Família e Cuidado Cultural.

\section{Desnutrição na ótica familiar}

Quando indagadas sobre a percepção familiar relacionada à desnutrição e causa, as mães deixaram evidente que desconhecem o tema em questão, pois, em sua concepção, filho desnutrido é aquele de corpo magro, embora saudável, ou esperto, mas fininho.

"Eu acho ela esperta, saudável. Nasceu fortinha, mas agora é descaída, fininha." (M1)

"Ele nasceu bem magrinho, mas foi na época certa, com nove meses. Eu achava que ele ia morrer, porque era tão desnutridinho. Pegava de dois panos. Hoje acho que vai ser normal, porque é mais forte." (M2)

Há resistência das mães em perceber ou admitir a desnutrição no filho pelo desconhecimento ou não-aceitação da doença ${ }^{(9)}$. Em contrapartida, o homem da zona rural revelou ideias simplistas sobre causas da desnutrição infantil na comunidade rural, como a dificuldade de a criança comer, sendo coagida com métodos não qualificados a alimentar-se.

"Dou um copo de leite, ela só toma a metade. Dou comida de panela, mas come pouco. Eu tenho que dá à força, é um trabalho medonho dar de comer a ela." (M1)

"Ele tem dificuldade de comer. Tem raiva de leite, eu dou à força, tem que apanhar pra beber o leite e pra comer." (M2)

As mães acreditavam que a causa da desnutrição estava na recusa de alimento pela criança. Ações de promoção da saúde devem trabalhar famílias para aperfeiçoar o saber científico ${ }^{(10)}$. Relatos incluíam: precária oferta de alimentos (aporte calóricoproteico), prematuridade, baixo peso ao nascer e introdução da alimentação complementar antes do sexto mês como fatores de risco para a desnutrição infantil crônica.

O papel materno nesse sentido é primordial, por gerar o bebê e, esperadamente, nutri-lo por diversos meses no início da vida. 
Além disso, apesar da inserção da mulher no mercado de trabalho, essa tende a se responsabilizar mais do que o companheiro (quando existente) pelos cuidados com os filhos ${ }^{(11)}$.

A alimentação adequada e balanceada mantém e desenvolve mecanismos bioquímicos e processos fisiológicos de tecidos e órgãos, além de constituir um direito básico das crianças. Os relatos demonstraram a disponibilidade de alimentos na mesa das famílias e o modo de serem ofertados aos filhos.

"Às vezes só tem o plantio, aí eu cozinho e dou pra ela comer feijão e milho." (M1)

"A gente passa por dificuldades, não tem comida. Quando tem o leite eu dou, o feijão ela come direitinho. Como está chovendo agora, a gente plantou o feijão e dá mais um pouco." (M3)

Após o primeiro ano, a alimentação baseia-se na redução de produtos industrializados e gordurosos, com preferência de frutas e verduras, ricos em vitaminas e minerais, indispensáveis para o crescimento e desenvolvimento infantil adequado(7). $O$ efeito protetor da alimentação iniciase com as práticas alimentares da infância e com o ato de amamentar e de oferecer dieta equilibrada para as crianças. $O$ consumo alimentar dos pais é determinante nas escolhas dos filhos e, portanto, responsável pela provável garantia de uma alimentação promotora de saúde ${ }^{(12)}$.

A oferta de alimentos às crianças relaciona-se com o orçamento familiar. Renda alta possibilita mais frutas, legumes e carboidratos. Entretanto, o baixo poder aquisitivo pode restringir a dieta a produtos do plantio como feijão e milho, comum na zona rural, na qual elevados índices de desnutrição decorrem da falta de aporte alimentar apropriado, essencial para o crescimento.

Ressalta-se que, para classes sociais menos favorecidas com empregos, remuneração adequada, possibilidade de consumo satisfatório de alimentos saudáveis para família, em especial as crianças, são relevantes Políticas Públicas de Saúde ${ }^{(13)}$.

Como problema de saúde pública, é ressaltado por alguns autores que a diarreia ocasiona casos graves e elevadas taxas de mortalidade em menores de 5 anos nos países em desenvolvimento, como o Brasil, devido a precárias condições de moradia, prematuridade, desmame precoce, situação vacinal incompleta e baixa escolaridade das mães ${ }^{(14-15)}$.

Infecções gastrointestinais, em especial diarreias, estão presentes de forma persistente e são fatores de risco para a desnutrição infantil por comprometer em graus variados a qualidade de vida das crianças, que são tratadas em domicílio com receitas caseiras, de acordo com as crenças da população.

"Quando tinha 1 ano, ele adoeceu, passou dias com diarreia, não comia nada. Não era assim uma diarreia, era só água. Ele ficou muito magro." (M1)

Portanto, é imprescindível estimular a comunidade a comparecer às unidades de saúde para profissionais qualificados avaliarem se o saber popular é adequado para resolver a patologia.

\section{Prejuízos da doença na família}

Foram analisados danos relacionados à desnutrição infantil no ambiente familiar, não resolvidos pelas mães por estarem habituadas à situação em que se encontravam os filhos, tornando-se fator cooperativo para o baixo crescimento e desenvolvimento das crianças.

"Ele não traz nenhum problema pra mim, só pra comer. Eu fico preocupada porque ele é ruim pra comer, tem fastio, não posso tá comprando todo mês vitamina pra dá." (M2)

Apesar de as mães exporem ausência de prejuízos para os filhos em decorrência da desnutrição, preocupavam-se com a situação alimentar da prole e desejavam transformar a realidade, mas não sabiam de que modo fazê-lo.

"Eu só chorava e achava ruim quando ele era doentinho, porque não comia nada, era só no soro. Só Deus mesmo que fez um milagre e tirou meu filho de lá." (M3)

A desnutrição, no cenário da atenção primária, deve ser percebida como problema social e não de saúde pública, visto que, em decorrência da natureza multifatorial, transcende o domínio dos profissionaisdesaúdeparaoplanejamento técnico e burocrático. Resultantes de intervenção governamental ou de forças externas, essas transformações têm afetado parte da população mundial, repercutindo em alterações significativas nas relações familiares. O profissional tem papel relevante na promoção da saúde, ao despertar na família a consciência crítica, viabilizando pontos positivos e negativos enfrentados no contexto social para a realização de determinada prática ${ }^{(6,7)}$.

\section{Cuidado cultural}

A desnutrição infantil é avaliada de forma ampla e complexa, incluindo estilo de vida da família e inter-relação de fatores como cultura e nível sociopolítico-econômico ${ }^{(16,17)}$. Os familiares se esforçavam dentro das limitações e condições financeiras para combater a desnutrição no cotidiano, utilizando ferramentas como o cuidado cultural, visando à resolutividade desse problema.

"Eu cuido bem dele. Quando fica doente, não gosto de levar pro doutor, eu mesmo faço o remédio em casa, faço lambedor, cozimento de eucalipto e de malvarisco pra dar banho, aí ele melhora, é melhor do que tomar antibiótico." (M2)

Os profissionais devem oferecer cuidado reflexivo e sistemático para reorganizar as práticas de saúde. A participação contribui para a redução da desnutrição e suas consequências por meio de programas de prevenção que envolvem 0 atendimento às famílias de crianças desnutridas. Os fatores interculturais podem ser realmente os indicadores críticos para a promoção e manutenção da saúde ${ }^{(18,19)}$. 
As mães afirmaram combater a desnutrição pela oferta de alimentos disponíveis em casa para as crianças, higiene do corpo, remédios caseiros para a cura das infecções respiratórias e gastrointestinais e uso dos serviços de saúde. O conhecimento não leva a mudanças de hábitos alimentares, sendo, portanto, imprescindível a educação nutricional. Atividades educativas que trabalhem conteúdos alimentares e busquem inseri-los na realidade dos indivíduos são conduzidas em qualquer ambiente, como escolas, creches, hospitais e centros comunitários, e podem promover mudanças de comportamento e de hábitos alimentares ${ }^{(12)}$.

A prática do cuidado é para assistência, apoio e facilitação ao indivíduo, a fim de aprimorar as condições de vida, embasadas na cultura, divisão e transmissão de valores, crenças e modo de vida de um grupo particular que guia pensamentos, decisões e ações relacionadas ao cuidado para aprendizagem subjetiva e objetiva, capacitando outros indivíduos ou grupos a manterem o bem-estar e a saúde ${ }^{(20)}$.

\section{CONSIDERAÇÕES FINAIS}

Cultura e crenças advindas por gerações influenciam a desnutrição infantil no âmbito familiar. Os pais, pela falta de conscientização, podem ser responsáveis pela patologia.
Existe discussão do tema, mas com pouca resolutividade, pois observaram-se índices elevados da doença e falta de funcionalidade de políticas públicas para promover a saúde.

Má alimentação, nível de escolaridade dos pais, gestações precoces, prematuridade/baixo peso dos recém-nascidos, introdução da alimentação complementar antes do sexto mês, falta de saneamento básico, qualidade da água consumida e dificuldades socioeconômicas comprometem a saúde de crianças que vivem em comunidade rural, em que as famílias sobrevivem da agricultura de subsistência. Apesar do esforço em combater a desnutrição infantil dentro do cotidiano, as mães não conseguem alcançar os objetivos almejados por falta de informação, insegurança, ansiedade e angústia em oferecer o melhor para o filho. No entanto, sabe-se que essa é uma responsabilidade da família e do poder público em todas as esferas.

Assim, considera-se a saúde uma complexidade, sobretudo na inter-relação de inúmeros fatores, como alimentação, moradia, educação, transporte, lazer e emprego. Portanto, espera-se a transformação da sociedade por políticas públicas, como promoção da saúde para a manutenção da qualidade de vida de crianças acometidas pela desnutrição.

\section{Referências}

1. Caldeira AP, França E, Perpétuo IHO, Goulart EMA. Evolução da mortalidade infantil por causas evitáveis. Rev Saúde Pública. 2005;39(1):67-74.

2. Lopes MSV, Vieira NFC. Cuidando da criança desnutrida, sobrevivendo apesar da adversidade do contexto familiar. In: Barroso MGT, Vieira NFC, Varela ZMV. Saúde da família II: espaço de incertezas e possibilidades. Fortaleza: Sociedade Brasileira de Enfermeiros Escritores; 2005. p. 43-56. 3. Batista Filho MA, Rissin A. A transiçăo nutricional no Brasil: tendências regionais e temporais. Cad Saúde Pública. 2003;19(1):181-91.

4. Sousa RP, Ramalho WM, Fortaleza BM. Pobreza e desnutriçãa: uma análise do Programa Fome Zero sob uma perspectiva epidemiológica. Saúde Soc. 2003;12(1):21-30.

5. Macêdo EMC, Amorim MAF, Silva ACS, Castro CMMB. Efeitos da deficiência de cobre, zinco e magnésio sobre o sistema imune de crianças com desnutrição grave. Rev Paul Pediatr. 2010;28(3):329-36.

6. Frota MA, Albuquerque CM, Linard AG. Educação popular em saúde no cuidado à criança desnutrida. Texto Contexto Enferm. 2007;16(2):246-53. 7. Silveira VG, Araújo PF, Louzada AVA, Frota MA. Conhecimento acerca da desnutrição infantil e do reaproveitamento alimentar: estudo de caso. Rev Tenden Enferm Profis. 2010;4(1):281-4.

8. Minayo MCS. Pesquisa social: teoria, método e criatividade. 29a ed. Petrópolis: Vozes; 2010.

9. Almeida MA. Combatendo a desnutrição infantil [Internet]. [citado em 2004 Mai 25]. Disponível em: http://federativo.bndes.gov.br/dicas. 10. Queiroz MV, Jorge MS. Estratégias de educação em saúde e a qualidade do cuidar e ensinar em pediatria: a interação, o vínculo e a confiança no discurso dos profissionais. Interface Comum Saúde Educ. 2006;10(19):117-30. 11. Vieira VL, Souza JMP, Mancuso AMC. Insegurança alimentar, vínculo mãefilho e desnutrição infantil em área de alta vulnerabilidade social. Rev Bras Saúde Matern Infant. 2010;10(2):199-207.

12. Verde SMML, Olinda QB. Educação nutricional: uma ferramenta para alimentação saudável. Rev Bras Promoç Saúde. 2010;23(3):197-98.

13. Martins MC, Frota MA. Fatores que interferem na utilização de alimentos regionais na cidade de Maranguape, Ceará. Cad Saúde Coletiva. 2007;15(2):169-82.

14. Black RE, Morris SS, Bryce J. Where and why are 10 million children dying every year? Lancet. 2003;361:2226-34.

15. Cauás RC, Falbo AR, Correia JB, Oliveira KMM, Montenegro FMU. Diarreia por rotavírus em crianças desnutridas hospitalizadas no Instituto Materno Infantil Prof. Fernando Figueira, Imip. Rev Bras Saúde Matern Infant. 2006;(1):77-83.

16. Frota MA, Barroso MGT. Repercussão da desnutrição infantil na família. Rev Latinoam Enferm. 2005;13(6):996-1000.

17. Frota MA, Sousa RMV, Sousa Filho OA, Barroso MGT. Diagnóstico das necessidades humanas básicas no contexto sociofamiliar de crianças desnutridas. Cogitare Enferm. 2007;12(2):198-203.

18. Frota MA, Martins MC, Santos RCAN. Significados culturais da asma infantil. Rev Saúde Pública. 2008;42(3):512-6.

19. Frota MA, Sousa RMV, Barroso MGT. Beliefs and cultural values of the undernourished child's family. Acta Paul Enferm. 2008;21(1):101-06. 20. Leininger MM. Culture care diversity and universality: a theory of nursing. New York: National League for Nursing Press; 1991. 